\title{
Archaeometric Analysis on Dūmat al-Jandal Pottery Assemblages A Focus on the Islamic Corpus
}

\author{
Simona Berardino, Romolo Loreto \\ University of Naples L'Orientale Department of Asian, African and Mediterranean Studies. \\ sberardino@unior.it; simonaberardino91@gmail.com \\ rloreto@unior.it; romololoreto@gmail.com; \\ Ombretta Tarquini, Marcello Colapietro \\ C.N.R. Institute of Crystallography (IC) - Research Area of the CNR of Rome 1, Montelibretti \\ ombretta.tarquini@ic.cnr.it; \\ marcello.colapietro@fondazione.uniroma1.it \\ Andrea Macchia \\ YOCOCU - YOuth in COnservation of CUltural Heritage \\ info@yococu.com
}

In the framework of the Italian Archaeological Mission in the Kingdom of Saudi Arabia, working at Dūmat al-Jandal, a first focus on the Islamic Pottery collected during the excavation of the Islamic core can be introduced, mainly from the area outside the so-called 'Umar ibn al-Khattab mosque. In order to define local production and the imported ones, and to classify groups according to the fabric features, ED-XRF, XRPD and Mineropetrographic characterization were performed in collaboration with C.N.R. Institute of Crystallography (IC) - Rome.

In this work, we report the results of the analysis of 35 samples, collected from a stratigraphic sequence involving the late pre-Islamic periods up to the 19th cent., that have been detected with the ED-XRF technique. Samples were analysed at normal atmospheric pressure with a Portable X-ray generator from EIS S.r.l. (Italy) with W anode, silicon drift detector thermo-electric cooled, equipped with Multi Channel Analyzer by Amptek inc. (USA). The data obtained from the XRF analysis were examined in order to define similarities and differences between the samples using PCA analysis (Fig. 1). The correlation matrix allowed to define the following three main variables association: 1) $\mathrm{Zr}, \mathrm{Ti}$, $\mathrm{Fe}$; 2) $\mathrm{Ca} \mathrm{Sr}, \mathrm{K}$; 3) $\mathrm{Cr}$, Mn. Based on PCA, the XRF data was plotted for the \% Fe, $\mathrm{Sr}$ and $\mathrm{Mn}$ or Ca. The Fe \% and earth alkali metals, depend on the main minerals characterizing the clay, influenced the macroscopic characteristics (color, ceramic body aspect...). Chromium and manganese are characteristic elements of accessory minerals and impurities, allowing us to obtain useful information on the origin of ceramics. 


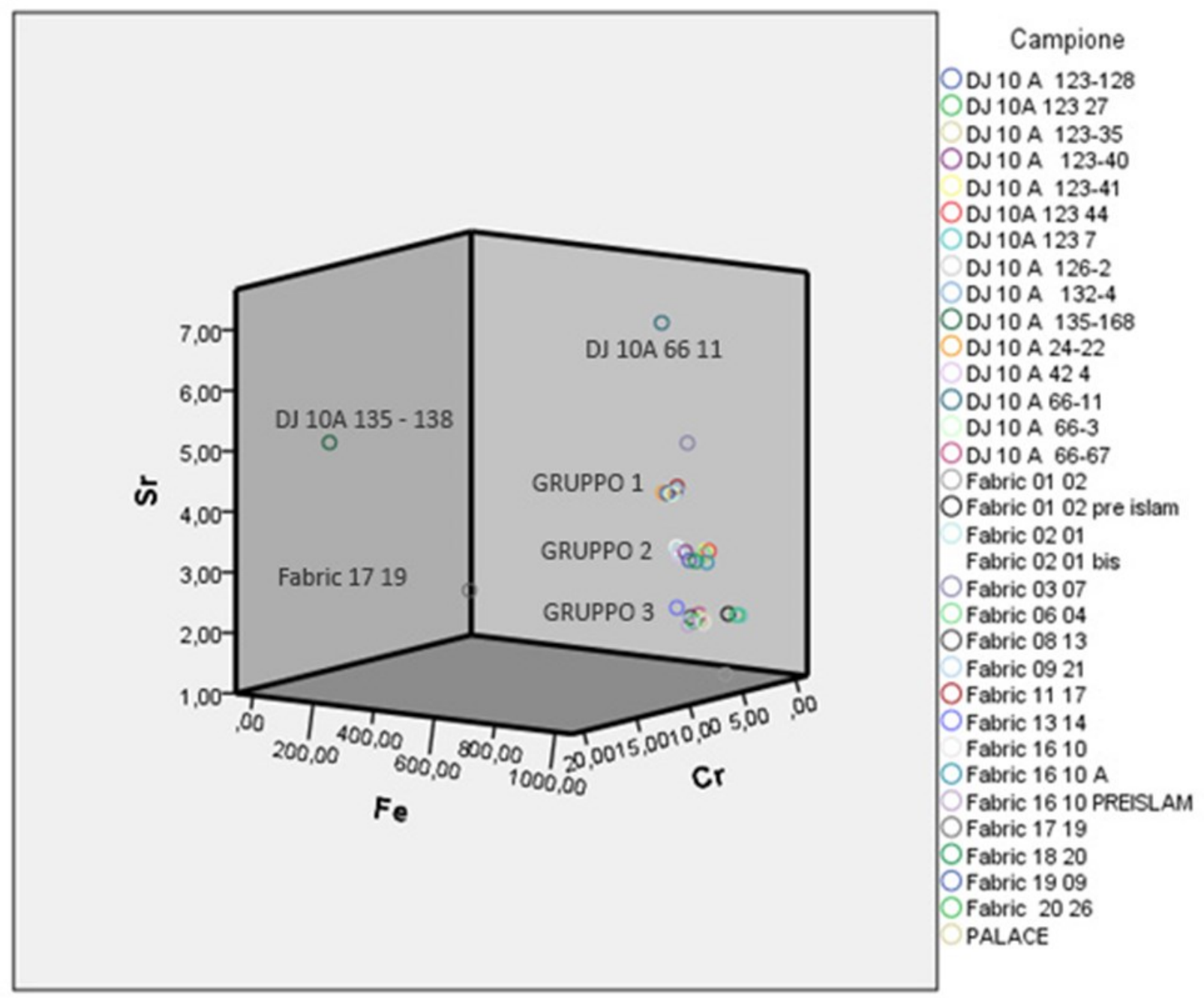

Fig. 1 Plotted samples based on Fe, Cr, Sr content.

The typological, morphological, and fabric analysis was reported in DUMA I and II reports (Charloux \& Loreto 2014, 2016) and at the 11th ICAANE (Loreto \& Berardino in press). The archeometric preliminary screening has allowed to organize samples into four groups (both late preIslamic and Islamic fabrics).

Fig. 2 shows the distribution of those fabrics that were considered (as working hypotheses) local. As it is possible to observe, most of the fabrics are significantly concentrated in groups 2 and $3 \mathrm{~A}$, while the remaining 3 groups have just one local fabric each. 


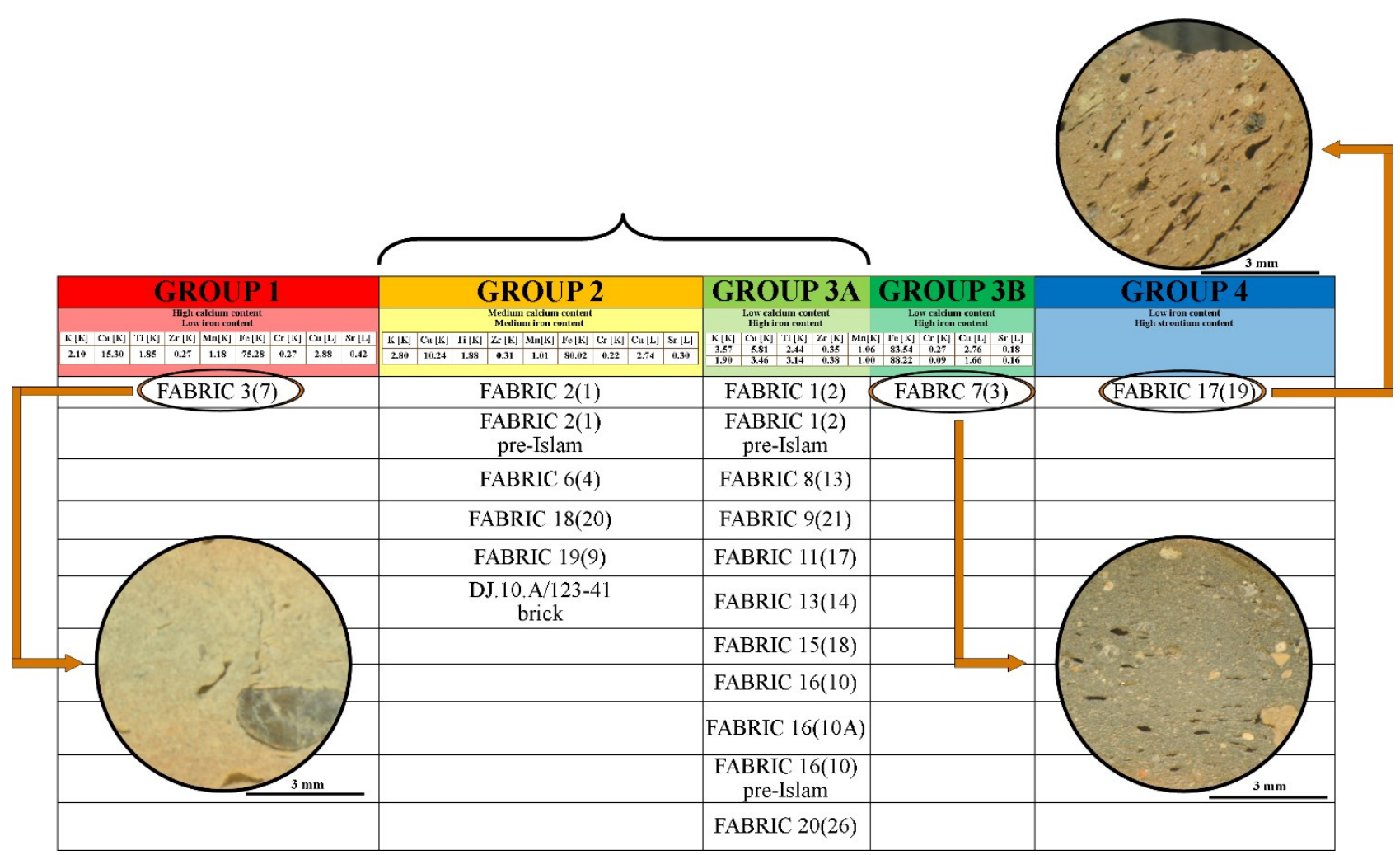

Fig. 2 Distribution of local fabrics.

The main result, the isolation of the three fabrics, might require us to reconsider our pottery organization. In addition, the peculiarity of the fabrics of groups 1, 3B and 4, and also, the similarity between fabric 11(17) and 13(14), are important results to verify in the continuation of the study. A greater definition of groups will be possible increasing the population samples. Finally, the study will continue about the relationship between the samples and raw clay analysis in order to investigate the exploitation of local sources: to contribute to the main issue of properly distinguish the pre-Islamic and Islamic fabrics in their stratigraphic contexts and regional trade.

\section{ACKNOWLEDGMENTS}

We would like to express our gratitude to all who support the ongoing research: Prof. Bruno Marcolongo, for his irreplaceable geoarchaeological support; Ahmad 'A. al-Qa'îd, director of the Archaeological and Ethnographic Museum of Dūmat al-Jandal; 'Abd Allah al-Zahrani and the members of the Ministry of Culture team; Prof. Augusto Pifferi, past Unit Responsible of the Institute of Crystallography of the Research Area of Rome 1 of the CNR; Fabrizio Censori, for his friendly collaboration and for the preparation of the samples; Prof. Vincenzo Francaviglia, for his general approach in overseeing the archeometric analysis. We are also grateful to all the students and colleagues partecipating in the field work during the pottery study processes. 


\section{BIBLIOGRAPHY}

Charloux, Loreto 2014

Charloux, G., Loreto, R. (eds.) Dûma 1. 2010 Report of the Saudi-Italian-French Archaeological Project at Dûmat al-Jandal. Riyadh 2014.

Charloux, Loreto 2016

Charloux, G., Loreto, R. (eds.) Dûma 2. The 2011 Report of the Saudi-Italian-French Archaeological Project at Dûmat al-Jandal, Riyadh 2016.

Loreto, Berardino in press

Loreto R., Berardino S., The pottery productions from Dumat al-Jandal. An outline from the Assyrian to the Islamic Era, in Proceedings of the workshop held at Munich April 2018. OREEA Oriental and European Archaeology, ed. by M. Luciani. Munich 2018. In press. 